Saudi Journal of Humanities and Social Sciences

Abbreviated Key Title: Saudi J Humanities Soc Sci

ISSN 2415-6256 (Print) | ISSN 2415-6248 (Online)

Scholars Middle East Publishers, Dubai, United Arab Emirates

Journal homepage: https://saudijournals.com/sjhss

Review Article

\title{
The Future of Pakistan Tourism Industry: A Review Paper
}

\author{
Sundas Shabbir ${ }^{*}$, Hamza Mughal, Maryam Iftikar, Malik Muhmmad Khan, Ayesha Anwar, Fazeel Akhter, Ammna Zubir
}

BS, Department of Tourism and Hospitality, Foundation University, Rawalpindi Campus, Pakistan

DOI: $10.36348 /$ sjhss.2020.v05i10.010 $\quad$ | Received: 26.09 .2020 | Accepted: 16.10 .2020 | Published: 21.10 .2020

*Corresponding author: Sundas Shabbir

\section{Abstract}

The Pakistan Tourism and Development Corporation (PTDC) recently added a revised website. The Pakistan Tourism and Development Corporation (PTDC) recently added a revised website. This aims to enhance Pakistan's tourism assets from north to south and recognize the country's capabilities. There is a huge population in Pakistan and the middle class are willing to fly, but it is not easy to travel to foreign destinations. Pakistan's population is approximately 212 million. With a growth rate of up to 2.1 percent, about 38 percent of the population is estimated to account for the growth of the middle class. These social, cultural, historical and natural assets should be recognised to be the real goods the government intends to sell. No further action, let alone the deprivation of the crime of providing this legacy to future generations of Pakistanis, would be taken if they are lost.

Keywords: Tourism, Pakistan, WTO, WTO.

Copyright (C) 2020 The Author(s): This is an open-access article distributed under the terms of the Creative Commons Attribution 4.0 International License (CC BY-NC 4.0) which permits unrestricted use, distribution, and reproduction in any medium for non-commercial use provided the original author and source are credited.

\section{INTRODUCTION}

It is fair to say that we don't need to be too inexplicable to understand that Pakistan's Tourism Industry is a history of dual thoughts of selfaggrandizement. Which changed from one extremist ideology to another extreme ideology. Our leadership has been trying to find external solutions, which has caused all aspects of our lives (from science to economics to governance) to lag. This is understandable because countries that follow others can only catch up. The fact that most people are suffering from mental illness is because people suspect these foreign social and economic improvement systems as another way to achieve disobedience and submission to our goals [1]. As the world was affected by a severe blockade, the blockade caused the company to close and segregated too many people in the industry from entering their homes, so forced introspection on the collective consciousness of a generation. Due to the stagnation of busy routines, many of us have the opportunity to understand and reassess our way of life. Again, this is an opportunity for governments to consider whether their efforts to improve the lives of the citizens they serve the best course of action.

\section{Why Tour and Travel are Important?}

If we are talking about Pakistan, "Tehreek-eInsaf' (PTI), then it is safe to say that the current government is trying to play a role in bringing tourism to the country. The PTI election manifesto has promised to bring the revolutionary benefits of tourism to Pakistan. The party promoted it on social media after it took power. The government seems to be defending this as a way to change the fate of Pakistan after it began Covid 19 crisis. Is the tourism industry the next big thing, and the profitable industry is profitable?" PTI will change tourism to improve Pakistan's international image and increase its direct contribution to GDP [2]. There is no doubt that Pakistan's tourism industry has great potential due to our diverse culture, traditions and natural gifts. But, for many reasons, including the war against Iraq, this is a currently missed opportunity. Terrorism in the public and private sectors and minimal marketing, infrastructure, and bad services.” -2018 PTI statement According to the United Nations World Tourism Organization, over the past two decades, travel and tourism have developed into one of the world's major economic sectors. Promoting development and social and economic growth worldwide. Data show that the tourism industry has changed dramatically from the emerging industry in the 1950s. Attracting 25 million inbound tourists to develop the industry quickly. Which reached a billion people in 2012, and Covid-19 is expected to nearly double in the 2030s. 
Therefore, it is not surprising that developing economies increasingly seek to improve this sector within their own countries. To attract the investment and employment benefits they bring.

Pakistan Tourism and Development Corporation (PTDC) recently added a revised website. That aims to enhance Pakistan's tourism assets from north to south and recognizes the country's ability[3]. Also, to challenge regional and global competition for a wide range of products. "Pakistan is rich in diverse flora and fauna. The Himalayas, Karakoram and Hindu Kush mountains and alpine meadows, perennial snow lines, coniferous forests in semi-alpine bushes and integration with the Sahara Desert, coastal and wetlands together, the vast Indus Plains provide extremely rich plants. And related wildlife, including endemic and migratory birds."Given that the PTI government has always expressed its willingness to tap this potential. It is necessary to understand what the proposals and initiatives mean to the country in the short and long term. And why there is an urgent need to guide this new development to protect wealth assets. Pakistan's natural, historical and cultural events when you learn from mistakes in other countries.

\section{Business Opportunities through Pakistan Tourism Industry}

In 2020, the World Travel and Tourism Council (WTTC) reported that the travel and tourism industry in 2019 continued to maintain a growth rate of $3.5 \%$, surpassing the growth of the global economy $(2.5 \%)$ for nine consecutive years. Tourism is the thirdlargest category of international exports, second only to chemicals and fuels, and worth US\$1.6 billion. Over the past five years, the sector has created a quarter of jobs and contributed approximately US\$8.9 trillion (10.4\%) to the global economy According to data from the World Tourism Organization, in 2018, inbound tourism in the Asia-Pacific region grew the fastest. Reaching $7 \%$, accounting for up to US $\$ 435$ billion in total tourism revenue. It leads to the growth rate of all other regions, second only to other regions, European tourism revenue [4].

At first glance, Pakistan currently accounts for only $0.1 \%$ of international tourism revenue of US\$352 million (2017). Which seems to be a disappointing proposition, but when examining the complex dynamics of tourism. It also shows that this is only part of a broader prospect. If global tourism expenditures are separated, international tourism expenditures only account for $28.7 \%$ of total expenditures. While domestic expenditures are the main expenditures, accounting for $71.3 \%$. When international tourism represents tourists to other countries, domestic tourism is defined as tourists travelling in their home country. This is the ideal starting point for Pakistan. Because, Pakistan has a large population and the middle class is eager to travel, but it is not easy to travel to international destinations. Pakistan's population is 212 million approximately. With a growth rate of up to $2.1 \%$ and the growth of the middle class is estimated to account for about $38 \%$ of the population.

\section{Middle-class travelers}

Travel is the desire of many Pakistanis, especially middle-class travellers. But they are restricted due to the difficulty of obtaining travel permits and visas from many international destinations and the high cost of travelling abroad [5]. This creates an opportunity for the Pakistan Tourism Industry to develop and expand the domestic tourism industry. Which can bring high profits and meet the domestic demand that the consumer sector highly hopes for?

When comparing at the regional level, Pakistan currently lags behind its regional counterparts and ranks 121st in the world. Its tourism indicators include supporting environment, policies and conditions, infrastructure and cultural resources are also in deficit. If viewed from a translucent perspective, Pakistan can be encouraged by the high international status of India and Sri Lanka and two countries with similar tourism products [6]. Emphasized that the products Pakistan intends to sell are sought after by international tourists. Also, to improve tourism, the government will have to improve many measures that will inadvertently improve the lives of Pakistanis. This path of development may not be the way Pakistanis want to improve their living standards, but given that the country has experienced crises in the recent past, they are likely to be happy to accept the improvements provided to you.

Similarly, the ability of the tourism industry to create jobs and indirectly have a positive impact in other sectors cannot be underestimated. Pakistan has a large workforce and a culture known as hospitality that can meet all the requirements for creating a selfsufficient business industry.

\section{Risks in Pakistan Tourism Industry}

However, it is necessary to fully consider the many potential risks of unsupervised tourism development to fully utilize the full potential of this beneficial but complex industry. Recent research by travel agencies shows that the country's most vulnerable to tourism development are those with a rapidly expanding middle class. They are classified as high-risk countries due to climate change, have the opportunity to over-rely on tourism, and have weak government management and existing structure.Most of these characteristics apply to Pakistan, so it is necessary to implement mitigation strategies before development is effective to protect the tourism industry from negative effects. Since the start of the tourism development project, correcting the facts and correcting damage to local tourism assets is much more expensive than conceiving and implementing the correct strategy [7]. 
After promising that wealthy countries have attracted tourism in many countries, recent erroneous studies have shown that the "intangible burden" caused by tourism has been identified as the destination's unaccounted cost of absorbing tourism. These may include environmental degradation, destruction of local lifestyles and pressure on existing infrastructure.At home, we can think of Murree as a small part of the tourism industry that may cause harm to its place and residents. Over the years, the influx of large numbers of tourists has reduced their ability to handle solid waste, and it turns out that their old infrastructure (not yet established to support so many users) has been under tremendous pressure [8].

If construction activities, solid waste and wastewater generation cannot be avoided, the local environment will cause significant or permanent loss of local biodiversity and ecosystem services. Most developing economies with weak infrastructure are extremely vulnerable to infrastructure pressures, including energy, solid waste disposal, and water and sanitation networks. Besides, the influx of tourists will increase local rents, overcrowding and negative impact on residents' privacy.

In general, even when developing countries implement tourism management, it only considers some external operating factors or the cost of increased tourism. Usually limited to managing and improving the existing airport and transportation network to accommodate visiting tourists. What the Pakistani government (in addition to the above measures) often loses and needs to be included in any new tourism management plan is to increase greenhouse gas emissions, protect natural ecosystems, restore ecosystem services, energy costs, water resources and wastewater management costs[9]. As the footprint of the area where tourism is proposed to increase is increased, which leads to the restoration and maintenance of society and culture, in many cases, tourism is considered a highly fragile ecosystem. It should be understood that these social, cultural, historical and natural assets are the real products that the government intends to sell. If they are destroyed, no further action will be taken, let alone the deprivation of the crime of delivering this heritage to future generations of Pakistanis [10].

\section{Leverage Potential Risks and Manage Risks}

To ensure that Pakistan's tourism industry can be developed in a way that maximizes its benefits and avoids risks; a systematic approach must be taken to assess the authenticity of the terrain and plan to implement the strategy [11].

UNEP and WTO recommend the following strategies when considering destination sustainability plans:

- A comprehensive look.
- Follow-up actions involving many stakeholders.

- Essential long term plan.

- Proper labelling with global and local impact.

- Promote sustainable consumption.

- $\quad$ Sustainable development and quality equality.

The UN Sustainable Development Goals (UNSDG) also addresses a wide range of issues raised by the tourism industry. This is not just another international commitment made by the Pakistani government, but it can already solve the country's problems due to poverty, hunger inequality and gender equality. Many problems faced.The process followed is to develop specific sustainable development guidelines for Pakistan by understanding and paying attention to indigenous areas of concern such as the United Nations Sustainable Development Goals (SDG) and the United Nations Environment Programme (UNEP)[12]. It then adopted and produced best practices and technologies that can mitigate the negative risks and costs of tourism. When creating this compliance path, some local laws and regulations, social and cultural aspects, climatic conditions and resource availability need to be considered. The final model for approval will need to strike a good balance between regulations and business promotion to avoid bottlenecks in approving and implementing development projects, but at the same time will not give up the need to protect domestic assets.

\section{Post Covid-19 effect on Pakistan Tourism}

At the time of writing, the world is still struggling to cope with the impact of Covid-19 on the tourism industry, but what we know is that borders are closed, flights are cancelled, and the value of the entire tourism industry is greatly destroyed. According to reports, Pakistan's national airline, Pakistan International Airlines (PIA), is one of the airlines most at risk of bankruptcy, and the Civil Aviation Authority estimates that it has lost 25 billion Pakistani rupees (only within two weeks after the shutdown). Hotels, resorts, and small and medium-sized enterprises across the country are highly closed and stressed, unable to pay employees' wages, and even risk bankruptcy. At the same time, Covid-19 has more than 100,000 cases and more than 2,000 deaths [13]. In hospital patients are running out of beds to care for admitted patients. The Prime Minister said that what is more worrying is that these cases have not yet reached their peak in August 2020.

\section{World Tourism Organization}

The World Tourism Organization estimates that by 2020, the number of global tourists may decrease by $20-30 \%$, which may cause a major blow to the emerging Pakistani tourism industry that proposes to support GDP. It is estimated that due to Covid-19, Pakistan's GDP in the 20th fiscal year may shrink by $13.6 \%$, and 11.5 million people will be in trouble due to the loss of temporary jobs [14]. Under high-impact 
conditions, about $50 \%$ of the population may fall into poverty. Long-term poverty. After examining the farreaching impact on the economy and companies, the positions of international organizations such as the World Tourism Organization and the World Health Organization are clear and said that people's well-being should be given priority when reopening the tourism industry [15].Our crisis management working group is developing standard operating procedures to open up the tourism industry. So when Covid-19 is over, we do not have to wait. We are trying to propose the next budget so that under the leadership of Prime Minister Imran Khan, various types of equipment that are exempt from customs duties are used in hotel kitchens and all hotels. Our goal is to the proportion of the country's tourism GDP has increased from $2.9 \%$ to $7-8 \%$ [16]. The Covid-19 crisis led to the need to provide solutions to support the faltering economy. And jump into development projects that are more attractive than ever before. The government will need to recognize these forces and develop innovative solutions from officials within its military. The steps taken now will become part of the performance score sheet and will be evaluated.

\section{CONCLUSION}

MoCC plays a key role in PTDC and must work together to provide leadership for the sustainable development of the tourism industry. Under the leadership of the current government, MoCC has made positive progress. Including major projects such as

- 10 billion tsunami trees.

- Plastic ban

- Clean Green Initiative

- Electric vehicle policy

- Consideration of launching green building

- $\quad$ That comes along with the standards to respond to the impact of tourism-related buildings.

For example, tourism planning, modelling, and the formulation of major legislation are some ways other countries adopt; try to avoid damage caused by tourism.

Take Pakistan as an example, where development funds equal to none. It may not be possible to get the latest technology for managing and maintaining tourism assets at all times. Thus, the strategy to use its largest assets: local institutions and a large workforce should place themselves at the core of any plan.

Ultimately, the direction taken by the Pakistani government to put in place its tourism strategy may have a direct impact immediately. In the worst case, it will have an irreversible impact on our natural, cultural and social environment. For Pakistani citizens, it is very important to work with the government at all stages of the development of the strategy. Also to get ownership of the plan that was developed consistently after the implementation of the plan.

\section{REFERENCES}

1. World Health Organization. Department of Mental Health, Substance Abuse, World Health Organization, World Health Organization. Department of Mental Health, Substance Abuse. Mental Health, World Health Organization. Mental Health Evidence \& Research Team. (2005). Mental health atlas 2005. World Health Organization.

2. Rehman, A., Ma, H., Irfan, M., Ahmad, M., \& Traore, O. (2020). Investigating the Influence of International Tourism in Pakistan and Its Linkage to Economic Growth: Evidence From ARDL Approach. SAGE Open, 10(2), 2158244020932525.

3. Arshad, M. I., Iqbal, M. A., \& Shahbaz, M. (2018). Pakistan tourism industry and challenges: a review. Asia Pacific Journal of Tourism Research, 23(2), 121-132.

4. Kanwel, S., Lingqiang, Z., Asif, M., Hwang, J., Hussain, A., \& Jameel, A. (2019). The influence of destination image on tourist loyalty and intention to visit: Testing a multiple mediation approach. Sustainability, 11(22), 6401.

5. Besio, K. (2007). Depth of fields: travel photography and spatializing modernities in northern Pakistan. Environment and Planning D: Society and Space, 25(1), 53-74.

6. Richter, L. K. (1989). The politics of tourism in Asia. University of Hawaii Press.

7. Ali, Y., Awan, M. A., Bilal, M., Khan, J., Petrillo, A., \& Khan, A. A. (2019). Risk assessment of China-Pakistan fiber optic project (CPFOP) in the light of multi-criteria decision making (MCDM). Advanced Engineering Informatics, 40, 36-45.

8. Khan, A. N., Collins, A. E., \& Qazi, F. (2011). Causes and extent of environmental impacts of landslide hazard in the Himalayan region: a case study of Murree, Pakistan. Natural Hazards, 57(2), 413-434.

9. Singh, S. P. (2007). Himalayan forest ecosystem services. Central Himalayan Environment Association, Nainital, Uttarakhand, India, 53.

10. Anjum, A. S., Zada, R., \& Tareen, W. H. (2016). Organic farming: Hope for the sustainable livelihoods of future generations in Pakistan. Journal of Rural Development and Agriculture, 1(1), 20-29.

11. Khalil, S., Kakar, M. K., \& Malik, A. (2007). Role of tourism in economic growth: Empirical evidence from Pakistan economy [with comments]. The Pakistan Development Review, 985-995.

12. Kumar, S., Kumar, N., \& Vivekadhish, S. (2016). Millennium development goals (MDGS) to sustainable development goals (SDGS): Addressing unfinished agenda and strengthening sustainable development and partnership. Indian journal of community medicine: official publication 
of Indian Association of Preventive \& Social Medicine, 41(1), 1.

13. Khan, N., Naushad, M., Akbar, A., Faisal, S., \& Fahad, S. (2020). Critical review of COVID-2019 in Pakistan and its impact on Pakistan economy. Available at SSRN 3629718.

14. Mela, K., Jyothi, M., Ijtema, B., Nazarene, B., \& Ijtema, R. T. (2020). Religious tourism and mass religious gatherings - The potential link in the spread of COVID-19. Current perspective and future implications. Travel Medicine and Infectious Disease, 36, 101786.

15. Yu, M., Li, Z., Yu, Z., He, J., \& Zhou, J. (2020). Communication related health crisis on social media: a case of COVID-19 outbreak. Current Issues in Tourism, 1-7.

16. Ali, A., Ahmed, M., \& Hassan, N. (2020). Socioeconomic impact of COVID- 19 pandemic: Evidence from rural mountain community in Pakistan. Journal of Public Affairs, e2355. 